\title{
Mapping Potential Risk for Housing Damage from Ground Movement Due to Climate Change
}

\author{
Simone Leao
}

\begin{abstract}
The performance of footings in residential construction is influenced by the degree of ground movement, particularly in reactive soils, which is driven by the magnitude of change in soil moisture. New patterns of climate are affecting residential foundations and causing serious and expensive damage. This paper produces a map of potential risk for housing damage from ground movement due to climate change. Using a geographic information system, it combines information on (1) soil moisture change related to climate, using TMI as the indicator, and (2) population growth. Preliminary results, having Victoria, Australia, in the last decade as the case study, suggest that effects of climate change on soil, and resulting impacts on house foundations, are not being taken into consideration in current planning strategies for urban development. Most of the urban growth priority zones in the study area are susceptible to medium and high risk for damage. Producing new and renovated buildings that are durable in the long term is essential for the economy, environment and social welfare. The map presented here can assist policies and strategies towards urban resilience in the context of climate change.
\end{abstract}

Index Terms-Risk mapping, housing damage, climate change, TMI.

\section{INTRODUCTION}

\section{A. Residential Construction in Reactive Soils in the Context of Climate Change}

Residential construction is a substantial part of the building industry in Australia. According to the latest Census of Population and Housing [1], there are 8.6 Million dwellings in Australia. And based on a Housing Industry Association report [2] there is an average of 155,000 new dwellings being built each year in Australia with a total investment of AUD 425 Billion. An additional AUD 323 Billion a year is also invested in renovation of existing dwellings. Victoria alone accounts for almost $30 \%$ of the national investment in new and renovated housing.

Producing new and renovated buildings that are durable in the long term is essential for the Australian economy, environment and social welfare. In the context of climate change, urban resilience is a goal that needs to be pursued by policies and strategies.

The majority of losses in catastrophes are due to weather-related events worldwide, such as windstorm, hurricane, tropical cyclone, hailstorm, flood, drought, wildfire, extreme temperature episodes, and sea level rise and

Manuscript received September 15, 2013; revised December 4, 2013

Simone Leao is with the School of Architecture and Built Environment, Deakin University, Victoria 3220, Australia (e-mail: simone.leao@deakin.edu.au). tidal surges [3]. Over the past 50 years the number of weather related natural disasters has been steadily rising. However, another important and often overlooked class of losses are related to small scale and long term weather-related processes, such as the residential damages caused by soil moisture change [4].

Light construction, such as low rise residential buildings, on expansive soil is a well-known engineering challenge [5]. Expansive soils are characterised by their typical behaviour of swelling in wet conditions and shrinking when it is dry [6] The resulting ground movement from soil moisture change can cause serious damage in the foundations of built structures. Therefore, an understanding of the potential adverse effects from reactive soils to the completed construction must be obtained before the design of the footing. Fityus and Buzzi [7] mention some common ways used to develop this understanding, such as on-site tests of soil profile, and laboratory testing of soil reactivity, together with generic climatic averages of temperature and rainfall for large areas where a site is located. However, they highlight that soil behaviour has a temporal aspect related to seasonality, which is often neglected. The current pace of climate change adds another dimension to the temporal aspect mentioned before. Ground movement does not only occur from the cyclic variability between seasons, but it seems that it can also be occurring based on the changing patterns of climate worldwide, particularly in the last decade.

A large number of dwellings built in the past, designed for climate conditions of that time, are now susceptible to new climatic patterns. In France, for example, subsidence-related losses caused by drought on reactive soils have increased by more than $50 \%$ within two decades, costing affected regions an average of EUR 340 million per year [3]. Losses from two droughts in the $1990 \mathrm{~s}$ amounted to US $\$ 2.5$ billion in the UK [8].

This is of concern also in Australia, which combines a large proportion of expansive soils and a noticeable change in its climate patterns in most of the regions. In terms of soil, approximately $30 \%$ of Australia and $50 \%$ of the surface area in Victoria (The Atlas of Australian Soils, [9]) are covered by moderate to highly expansive soils. In terms of climate change, Australia has warmed almost $1^{\circ} \mathrm{C}$ over the last century, and there have been significant regional trends in rainfall with the northern, eastern and southern parts of the continent receiving greater rainfall and the western region receiving less. CSIRO projections for future climatic changes indicate increases in annual average temperatures of $0.4-2.0^{\circ} \mathrm{C}$ by 2030 (relative to 1990 ) and $1.0-6.0^{\circ} \mathrm{C}$ by 2070. Considerable uncertainty remains as to future changes in rainfall [10]. 
In Victoria, Australia, footing and slab defects in residential construction have the highest average defect cost; and all housing defects cost nearly AU\$1 billion per annum [11]. Holland [12] in his book on the design, performance and repair of housing foundations, investigated a large number of samples and concluded that about $50 \%$ of the housing failures in Victoria occurred in moderately to highly expansive soil.

\section{B. The Role of TMI: The Thornthwaite Moisture Index}

Geographer C W Thornthwaite [13] proposed a moisture index based on the concepts of effective precipitation and potential evapotranspiration (PET) as part of a water balance model for a new classification system for climate. Positive values for TMI indicate that precipitation exceeds evaporation, and that there is a potential surplus of moisture in the area. On the other hand, negative values of TMI indicate deficit of water caused by evaporation above precipitation.

The wetness of the surface is essential for understanding a variety of biophysical and biological processes. For this reason, TMI has been employed since the late 1940s, when it was first proposed, to the present across a diverse range of research areas. Applications include suitability for agriculture [14], road infrastructure management [15]-[17], water resource and vegetation [18], and light urban construction [19].

The Australian Standard 2870 provides guidelines and performance requirements for the design of footing and slab systems, with an emphasis to the issue in sites with reactive soils and significant ground movement [20]. Section 2 of AS 2870 addresses the site classification and investigation requirements. It presents a map of climatic zones for the state of Victoria, based on the TMI classification, and relates these zones to different soil profiles. This map is suggested by the Standard to be used, together with other local analysis, as a guide to the design of light construction foundations. The AS 2870 TMI map was produced using climate data from the 1970s, and does not reflect the current climate conditions in the region.

Few researchers have investigated the role of TMI in climate change studies. McCabe and Wolock [21], for example, examined the effects of long-term changes in climate (temperature and precipitation) on the Thornthwaite moisture index in the Delaware River Basin/USA. AustRoads [15] analysed the impacts of a climate change scenario, using TMI as an indicator, on the conditions of existing and proposed road infrastructure in Australia. Lopes and Osman [19] used TMI mapping to infer the effect of climate change on the shallow expansive foundation conditions of light construction in Victoria/Australia. Leao and Osman-Schlegel [22] have produced a series of accurate TMI maps for a period of 100 years in Victoria, Australia, and estimated that almost $30 \%$ of the surface of the state has changed its climatic zone according to the TMI classification in the last 20 years. This is very important, because although a static map of TMI can inform the state of a region at a certain moment in time, it cannot express the process of change over time. The latter is particularly important when addressing climate process nowadays, in order to understand how the current situation was formed from the past, and also how the future can be under some scenarios.

It is advocated here that even more important than knowing the TMI climatic zone of an area at a certain point in time, is knowing how TMI has been changing over time in that area. In regions experiencing significant changes, this knowledge can assist in developing an understanding of tendencies and a context to investigate implications of such changes for different uses of the area. This paper aims to contribute to this goal, by co-relating the areas of significant TMI change in Victoria in the last 10 years with the areas with significant population growth at the same time. Regions that combine simultaneous large changes in TMI and increasing population may represent a high risk for residential damage, considering the potential situations of a large number of new dwellings constructed based on wrong parameters related to the behaviour of the soil. With this aim, a map has been produced indicating the potential risk for housing damage from ground movement due to climate change in Victoria, using a geographic information system (GIS). Preliminary results suggest that a majority of the area of the state presents low risk for damage; however, most of the urban growth priority zones according to the current Urban Plan Zoning Scheme are within the regions with medium and high risk for damage. This paper presents a closer look at one of these regions, in the City of Greater Geelong in Victoria.

\section{MethodOLOGY}

This paper progresses on the previous research that produced a time series of TMI maps for the State of Victoria, Australia, and the assessment of TMI change over time, particularly the recent significant changes over the past 10 years [22]. Therefore, Victoria is used as the case study.

In order to estimate the potential risk for house damage from ground movement due to climate change, this study has combined two inputs: (1) a map of TMI change in Victoria for the last 10 years (from 2001 to 2011); and (2) a map of population growth in Victoria by LGA (Local Government Area) for the same period. The period has been chosen based on the available data from the Socio-demographic Census in Australia. Although Leao and Osman-Schlegel [22] have produced TMI maps over the last century in previous research (from 1913 to 2012, divided in periods of 20 years), a new TMI change map had to be produced for this study in order to get aligned with the Census dates. The same methodology was used for the production of the new maps. The maps are in a format appropriate for the GIS analysis using ArcGIS 10.1. They are vector maps with GDA 1994 MGA Zone 55 projection system.

Each one of the two maps had their original attributes classified into four levels: 0) No change; 1) small change; 2) medium change; and 3) large change, respectively. Table I indicates the thresholds used for the classification of the two maps.

After the classification presented above, the two maps were combined, through a mathematical multiplication process (map algebra), resulting in a third map. Table II 
presents the possible results from this combination. The attributes of the new map range from a minimum of 0 , which indicates areas in which there hasn't been any change in TMI and neither increase in population, to a maximum of 9, which indicates areas in which there has been both large change in TMI and significant increase in population. The intermediate attributes indicate a number of different combinations of these changes.

TABLE I: CLASSIFICATION SCHEME FOR TMI CHANGE AND POPULATION GROWTH MAPS

\begin{tabular}{|c|c|c|}
\hline & TMI change map & Population growth map \\
\hline & $\begin{array}{l}\text { TMI Change }= \\
{\left[\operatorname{Abs}\left(\mathrm{TMI}_{2011}-\mathrm{TMI}_{2001}\right)\right]^{+}}\end{array}$ & $\begin{array}{l}\text { POP Change }= \\
{\left[\text { Pop }_{2011}-\text { Pop }_{2001}\right]}\end{array}$ \\
\hline & Unit: dimensionless & Unit: inhabitants \\
\hline (0)No change & TMI Change $=0$ & POP Change $<=0$ \\
\hline (1)Small change & TMI Change $=1-5$ & POP Change $=1-5,000$ \\
\hline $\begin{array}{l}\text { (2)Medium } \\
\text { change }\end{array}$ & TMI Change $=6-10$ & POP Chg $=5,001-15,000$ \\
\hline (3)Large change & TMI Change $>10$ & POP Change $>15,000$ \\
\hline
\end{tabular}

TABLE II: MATRIX OF THE POSSIBLE COMBINATIONS BETWEEN TMI CHANGE AND POPULATION GROWTH

\begin{tabular}{|c|c|c|c|c|c|}
\hline & & \multicolumn{4}{|c|}{ Population Growth } \\
\hline & & $\begin{array}{c}\text { No } \\
\text { change } \\
(0)\end{array}$ & $\begin{array}{c}\text { Small } \\
\text { change } \\
(1)\end{array}$ & $\begin{array}{c}\text { Medium } \\
\text { change } \\
(2)\end{array}$ & $\begin{array}{c}\text { Large } \\
\text { change } \\
\text { (3) }\end{array}$ \\
\hline \multirow{4}{*}{$\begin{array}{c}\text { TMI } \\
\text { change }\end{array}$} & No change $(0)$ & 0 & 0 & 0 & 0 \\
\hline & Small change (1) & 0 & 1 & 2 & 3 \\
\hline & Medium change(2) & 0 & 2 & 4 & 6 \\
\hline & Large change(3) & 0 & 3 & 6 & 9 \\
\hline
\end{tabular}

The attributes presented in Table II have been classified again into four levels, but this time the meaning of the levels are not related to the changes themselves, but the potential risks for house damage associated to the respective combination of changes. Table III presents the thresholds used in this new classification.

TABLE III: CLASSIFICATION SCHEME FOR THE POTENTIAL RISK FOR HOUSE DAMAGE ASSOCIATED WITH TMI CHANGE AND POPULATION GROWTH

\begin{tabular}{|c|c|c|}
\hline Risk & $\begin{array}{l}\text { Combined score: } \\
\text { TMI change } * \\
\text { POP Change }\end{array}$ & Description \\
\hline (0) No risk & 0 & $\begin{array}{l}\text { - No change for both TMI and } \\
\text { population. }\end{array}$ \\
\hline (1)Low Risk & $1-2$ & $\begin{array}{l}\text { - Small change for both TMI and } \\
\text { Population; or } \\
\text { - Small change for one map and } \\
\text { Medium change for the other map. }\end{array}$ \\
\hline $\begin{array}{l}\text { (2) Medium } \\
\text { risk }\end{array}$ & $3-4$ & $\begin{array}{l}\text { Small change in one map and } \\
\text { large change in the other map; or } \\
\text { - Medium change for both maps. }\end{array}$ \\
\hline (3) High risk & $6-9$ & $\begin{array}{l}\text { - Medium change in one map and } \\
\text { large change in the other map; or } \\
\text { - Large change in both maps. }\end{array}$ \\
\hline
\end{tabular}

\section{RESUlTS AND DisCUSSION}

\section{A. The State of Victoria}

Fig. 1 presents the spatial distribution of the population growth in Victoria between 2001 and 2011, according to the four classes of population change defined in Table 1 . It is possible to see that although most of the area of the state had small or no population growth, the medium and large population growth occurred in areas already very urbanised, including parts of Metropolitan Melbourne, Greater Geelong, Greater Bendigo and Mornington Peninsula. This is expressed by the overall area and the average density of the group of LGAs within each class of population change (Table IV).

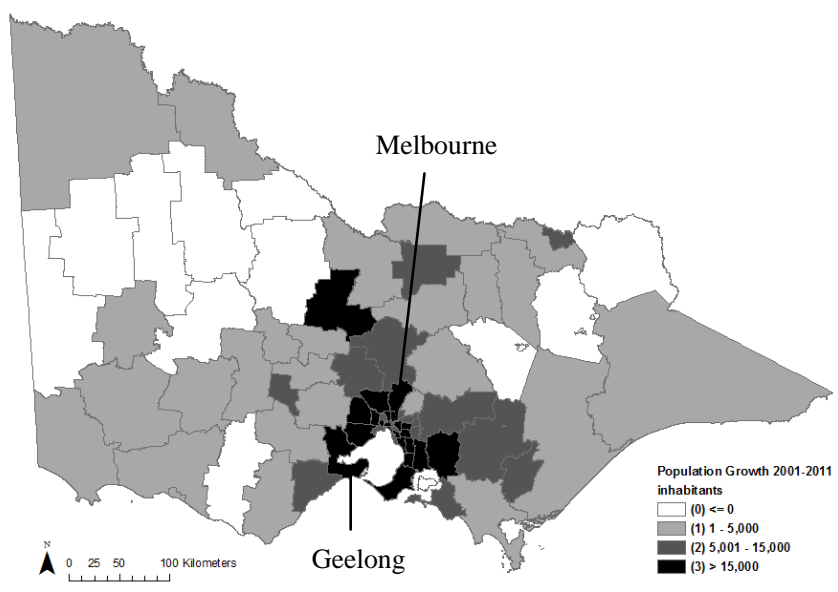

Fig. 1. Level of population growth in Victoria from 2001 to 2011.

TABLE IV: LGAs, AREA, POPULATION AND AVERAGE DENSITY By LEVEI OF POPULATION GROWTH IN VICTORIA (2001-2011)

\begin{tabular}{|c|c|c|c|c|}
\hline Pop change & $\begin{array}{l}\text { Number } \\
\text { of LGAs }\end{array}$ & $\begin{array}{l}\text { Area } \\
\text { LGAs } \\
\left(\mathrm{Km}^{2}\right)\end{array}$ & $\begin{array}{c}\text { Pop LGAs } \\
\text { in } 2011\end{array}$ & $\begin{array}{c}\text { Average } \\
\text { density } \\
\text { (persons } / \mathrm{km}^{2} \text { ) }\end{array}$ \\
\hline$(0)<=0$ & 13 & 68,120 & 100,113 & 1.5 \\
\hline (1) 1 to 5,000 & 26 & 130,562 & 627,293 & 4.8 \\
\hline $\begin{array}{l}\text { (2) } 5001 \text { to } \\
15000\end{array}$ & 19 & 19,086 & $1,567,683$ & 82.1 \\
\hline (3) $>15000$ & 22 & 9,632 & $3,239,437$ & 336.3 \\
\hline Sum & 80 & 227,400 & $5,534,526$ & \\
\hline
\end{tabular}

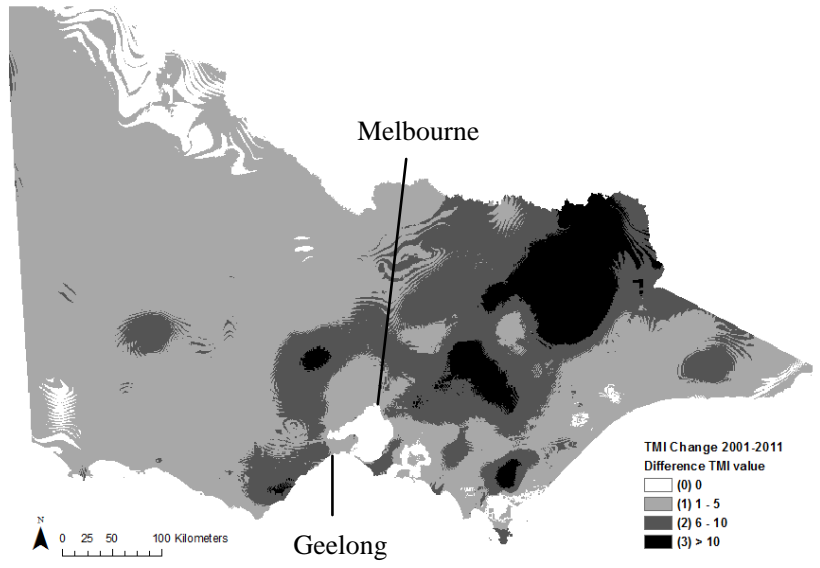

Fig. 2. Level of TMI change in Victoria from 2001 to 2011

Fig. 2 presents the spatial distribution of TMI change in Victoria between 2001 and 2011, according to the four classes of TMI change defined in Table I. Table V provides details on the area and \% of the state covered for each class of change. It is possible to see that most of Victoria had small or no TMI change (approximately 71\%). Also, most of the areas 
with large TMI change are located in the alpine region, which is sparsely urbanised. However, the region with medium TMI change, which covers around $21 \%$ of the state, is located in some of the mostly urbanised regions of the state.

TABLE V: AREA OF THE STATE (AND \%) BY LEVEL OF TMI CHANGE IN

\begin{tabular}{|c|c|c|}
\hline \multicolumn{3}{|c|}{ VICTORIA (2001-2011) } \\
\hline TMI change & Area $\mathrm{km}^{2}$ & $\%$ \\
\hline (0) 0 & 9,987 & 4.4 \\
\hline (1) 1 to 5 & 152,013 & 66.8 \\
\hline (2) 6 to 10 & 48,644 & 21.4 \\
\hline (3) $>10$ & 16,756 & 7.4 \\
\hline
\end{tabular}

Fig. 3 and Table VI present the result of the combination of the two previous maps, indicating the potential risk for house damage from ground movement due to climate change in Victoria, based on the context of the last 10 years. $34.3 \%$ of Victoria presents no potential risk for house damages, based on the criteria used in this study. The majority of the State $(54.4 \%)$ presents low potential risk. In these areas there has not been significant TMI change and/or population growth in the past 10 years.

However, although the areas with medium and high potential risk account for little more than $11 \%$ of the state surface, they are located in the most urbanised portions of the state, including metropolitan Melbourne and the surrounding regions.

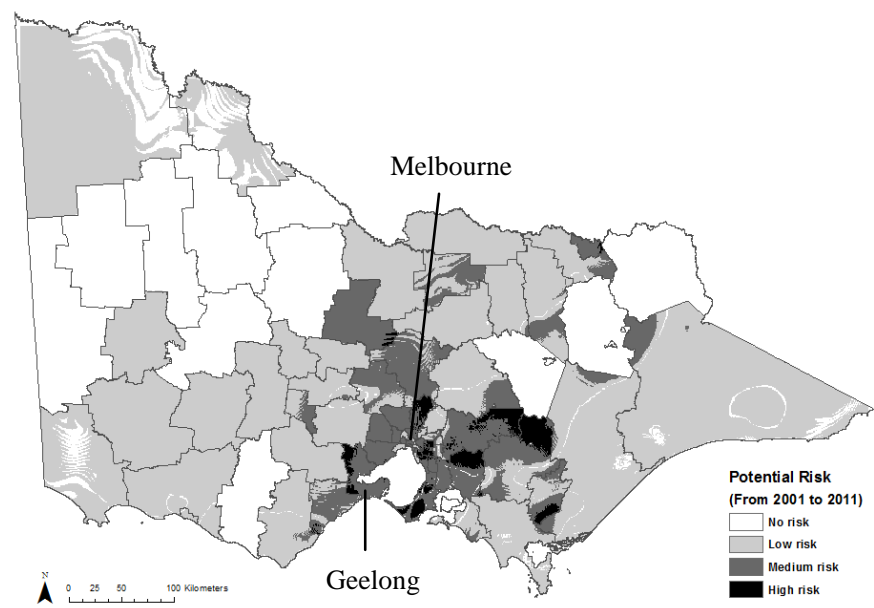

Fig. 3. Potential risk for house damage due to ground movement from climate change in Victoria (2001-2011).

TABLE VI: AREA OF THE STATE (AND \%) BY LEVEL OF POTENTIAL RISK FOR HOUSE DAMAGE IN VICTORIA (2001-2011)

\begin{tabular}{|c|c|c|c|}
\hline & TMI change & Area $\mathrm{km}^{2}$ & $\%$ \\
\hline$(0)$ & No Risk & 78,045 & 34.3 \\
\hline (1) & Low Risk & 123,657 & 54.4 \\
\hline (2) & Medium Risk & 22,146 & 9.7 \\
\hline (3) & High Risk & 3,552 & 1.6 \\
\hline
\end{tabular}

\section{B. The City of Greater Geelong}

In order to better assess the resulting map, this paper zooms-in at one selected area, the City of Greater Geelong (CoGG). CoGG is located 75 kilometres south-west of the state capital, Melbourne. It is Victoria's second largest metropolitan area, after Melbourne, and Australia's 12th most populous. It currently houses one of the largest urban growth fronts of the country, designed for approximately 65,000 new residents in the next two decades.

Fig. 4 presents the average TMI for the CoGG over the last century, from 1912 to 2011 , divided in 10 year intervals $\left(T_{1}\right.$ to $\mathrm{T}_{10}$ ). It demonstrates that TMI has remained similar over the first 80 years (from 1912 to $1981, \mathrm{~T}_{1}$ to $\mathrm{T}_{7}$ ), with slight variability around an average. However, TMI has progressively decreased over the last three decades (from 1982 to $2011, \mathrm{~T}_{8}$ to $\mathrm{T}_{10}$ ), and particularly in the last decade (2002-2011, $\mathrm{T}_{10}$ ). This means the region is getting drier in general. The average TMI for the period 1912-1981 was $-12.6( \pm 1.5$, st dev $)$. This was reduced to $-16.5( \pm 2.5$ st dev $)$ for the period 1982-2011. This is aligned with findings from previous research that indicated the trend of drying climate conditions in Victoria [4]-[10] and also the acceleration of climate change processes in the last decade [10].

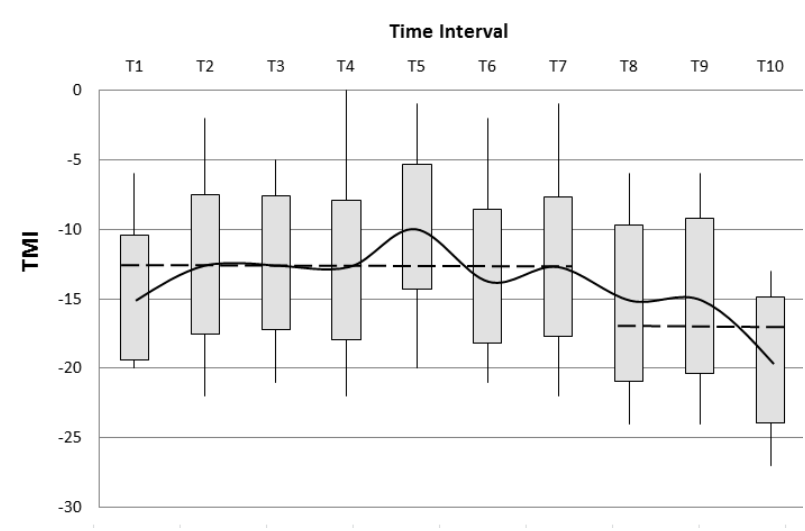

Fig. 4. Average TMI in CoGG, from $1912\left(\mathrm{~T}_{1}\right)$ to $2011\left(\mathrm{~T}_{10}\right)$.

Census data from 1991 to 2011 indicates a steady rate of growth in the CoGG, higher than the average of Australia and Victoria. The projections for population growth in CoGG over the next 20 years developed by the Victoria's Department of Planning and Community Development [23] indicate the continuation of this trend (Figure 5). CoGG is expected to have almost 90,000 new residents by 2031, from the latest population count in 2011, and most of this population is expected to be housed in the urban growth zone.

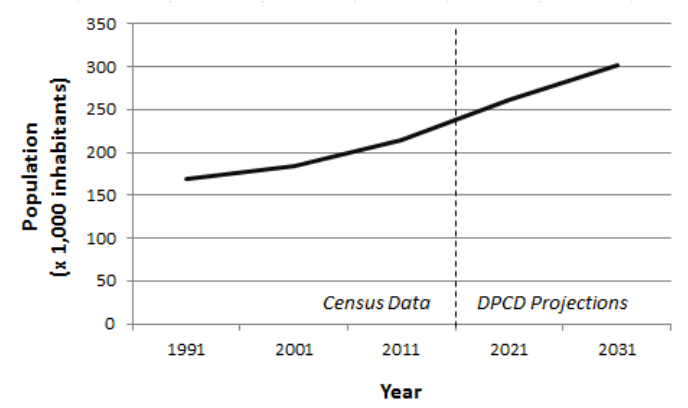

Fig. 5. Population growth trend in the city of Greater Geelong, past and projected (1991-2031).

Based on the map produced in this study representing the potential risk for house damage from ground movement due to climate change in Victoria, Fig. 6 shows that there is no land with no risk in CoGG, and only $1 \%$ has low risk. On the other hand, the wide majority of the region presents medium risk $(73 \%)$, and $26 \%$ present high risk. The CoGG has a higher risk when compared to the whole state. This is because 
it combines significant levels of both population growth and TMI change. Fig. 5 also shows that the current Urban Growth Zone for the CoGG is located in an area classified as potentially subject to high risk of house damage from ground movement due to climate change. The urban growth zone in CoGG is one of the largest growth fronts in the country [24]. It consists of 2,500 hectares of developable land located as a southern extension of the existing urbanization, able to house between 55,000 to 65,000 new residents. Land started to be released in 2010, and construction of new dwellings is occurring rapidly in the area (Fig. 7).

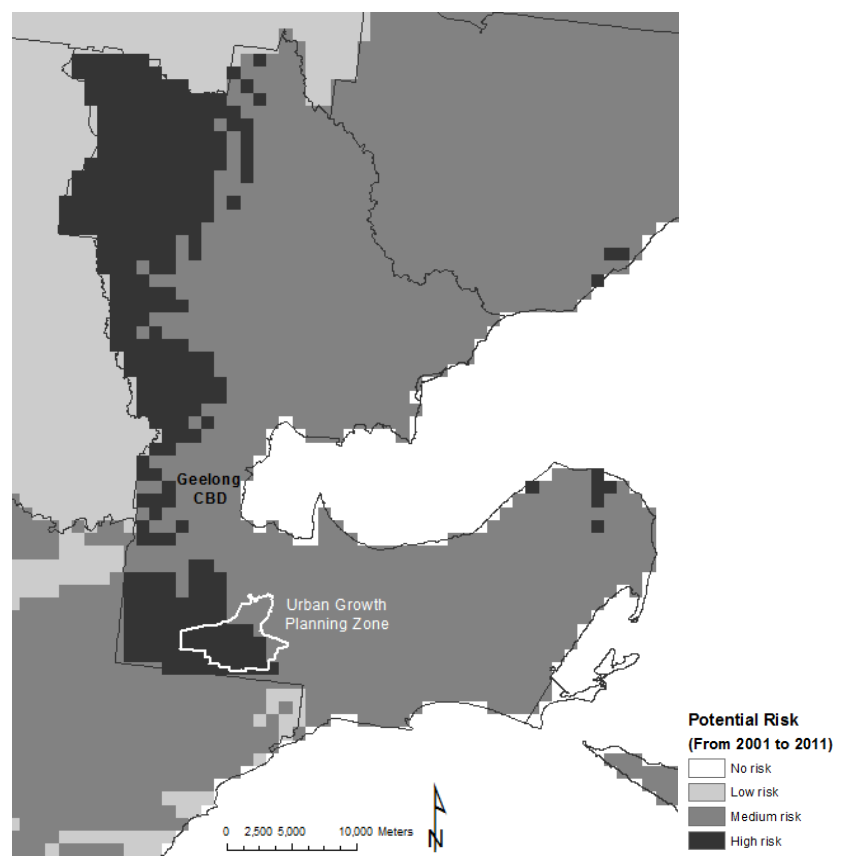

Fig. 6. Potential risk for house damage due to ground movement from climate change in the CoGG (2001-2011).

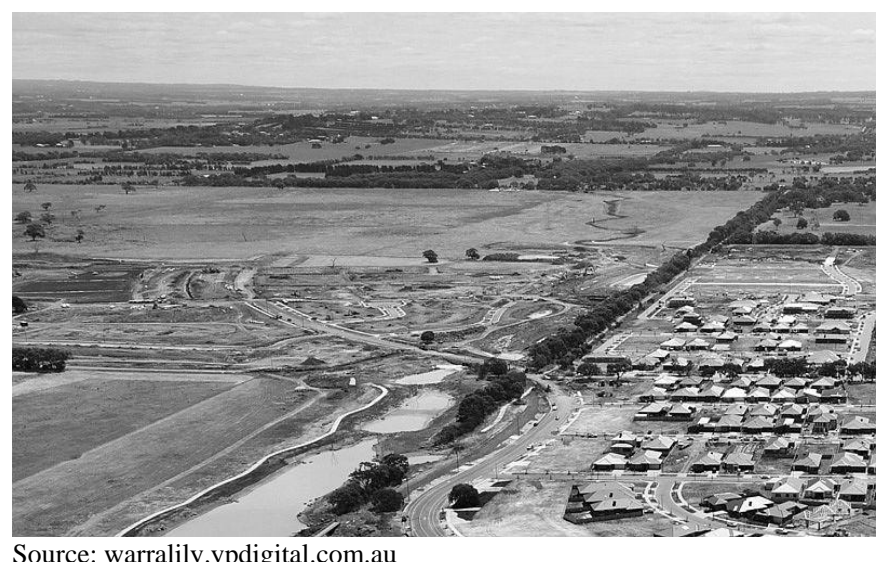

Source: warralily.ypdigital.com.au

Fig. 7. Residential construction in the urban growth zone in the CoGG, 2013.

\section{CONCLUSION}

The accelerated symptoms of climate change demonstrate the impacts of modern urbanisation. Increased temperatures and weather-related disasters are a result, in significant part, from the intensive production of greenhouse emissions typical of our cities. Housing research has increasingly been involved with climate change issues. This present paper highlights one aspect within this context: the impact of climate change on soil moisture, and its further effect on causing residential foundation damage.
TMI mapping, as reported in many different applications in the literature worldwide, has been used to classify climate zones according to its moisture index for a specific point in time. This is a limited use that does not explore to full extent the capacity of TMI as an important climate index. Previous study developed by the author of this paper [22] indicated that significant change of TMI has occurred in Victoria in the last century, particularly in the last two decades. Victoria is getting drier; almost $30 \%$ of the surface of Victoria has changed its TMI climate zone. The understanding of this trend is very important in order to assess potential impacts of TMI change on existing residential stock. Drier conditions can intensify subsidence-related damage in dwellings. The housing stock built in Victoria in the last three decades has used the AS 2870 TMI map [20] as a guideline which is out of date. Part of this stock is located in areas in which soil moisture has changed as a response to new climate patterns. The location and quantification of the existing stock at risk of damage from soil moisture change can be introduced in strategies for retrofitting. Current literature on research and practice for urban retrofitting is focused on technologies and systems to produce residential units which use less energy, use required energy more efficiently, and produce less greenhouse emissions as a way to mitigate the effects of climate change. Those retrofit initiatives can be less effective in achieving their goals if a dwelling is susceptible to structural damages caused by subsidence or heave processes, such as cracks and leaks in walls, floor and duct elements.

This paper progressed upon this previous work, investigating how this change relates to the patterns of urban growth in Victoria. Emphasising the last 10 years, it was possible to see that most of the urban growth, and consequently the residential construction, occurred in areas with significant TMI change. As a consequence, most of the new residential constructions in the state are located in regions classified as having medium and high risk of housing damage caused by ground movement due to climate change. This situation demonstrates that the effect of climate change on soil moisture has not been taken into account in plans and strategies for present and future urbanisation. A closer look at the City of Greater Geelong confirmed this context. The recently started new urban growth development, which is presented as a sustainable design in its strategic plan, is located in an area with high risk for housing damage. It also demonstrates a lack of coordination between different bodies associated to the built environment. While the State and Local Governments have intentions of producing a sustainable neighbourhood, the Australian Standard proposes guidelines for construction which are partly out-of-date (the TMI map is based on climate data from the 1970s), and the developers produce new residential units without an understanding of the effects of climate change on soil.

This paper presented a preliminary exercise of the contribution that a TMI change map can have to assist in planning and building more resilient urban areas. The map of potential risk for house damage from ground movement due to climate change indicates 'potential' for damage only. More information is required in order to obtain a detailed assessment of the level of risk, particularly related to the type of soil. Reactive soils, which cover around $50 \%$ of the state of 
Victoria [9] are subject to significant ground movement. Moreover, the behaviour of different reactive soils varies according to the climatic zone they are exposed to (TMI class). For example, in areas with limestone clays, a change of TMI from Zone 1 (TMI>40) to 2 (TMI: 10 to 40) does not imply difference in soil reactivity; the soil is highly reactive in both situations. However, if TMI Zone changes from 2 (TMI: 10 to 40 ) to 3 (TMI: -5 to 10 ) in the same region (limestone clays), the reactivity of the soil increases from high to extreme [20]. In order to capture this, further research should analyse the combined effect of TMI with the type of soil.

This study is another step in the continuing research in urban resilience. The ultimate goal of the broad research is to develop a dynamic model, based on continuous monitoring of TMI, to assist in retrofitting and adaptation strategies for existing and new housing stock. Residential construction is a substantial part of the building industry in Australia. Producing new and renovated buildings that are durable in the long term is essential for the Australian economy, environment and social welfare.

\section{ACKNOWLEDGMENT}

This research was supported by the School of Architecture and Built Environment of Deakin University. The author wishes to gratefully acknowledge the contributions of Linda Osman-Schlegel, lecturer in Construction Management at Deakin University, and Dominic Lopes, Chair of HEDRA/Housing Engineering Design \& Research Association. I also would like to thank David Pegg, cartographer at Geomatic Technologies, for his revision of the text and valuable comments.

\section{REFERENCES}

[1] ABS, Australian Bureau of Statistics. (July 20, 2013). 2011 Census of Population and Housing: Community Profiles. [Online]. Available: http://www.censusdata.abs.gov.au/census_services/

[2] HIA, Housing industry Association, HIA National Outlook, Autumn Edition, 2012, Australia.

[3] E. Mills, "Climate change, insurance and the building sector: technological synergisms between adaptation and mitigation,' Building Research \& Information, vol. 31, no. 3-4, pp. 257-277, 2003.

[4] N. Y. Osman and D. Lopes, "Thornthwaite moisture index as a measure of climate changes," in Proc. the 2008 Foundation and Footing Society workshop, Foundation and Footing Society, Adelaide, South Australia, 2008.

[5] M. E. Popescu, "Engineering problems associated with expansive clays from Romania," Engineering Geology, vol. 14, issue 1, pp. 43-53, 1979.

[6] J. D. Nelson and D. J. Miller, Expansive Soils: Problems and Practice in Foundation and Pavement Engineering, USA, John Wiley \& Sons, 1992.

[7] S. Fityus and O. Buzzi, "On the Thornthwaite Moisture Index to infer depths of seasonal moisture change," Australian Geomechanics, vol. 43, no. 4, pp. 43-54, 2008.

[8] M. S. Ruquet, "Contractors insurance crisis spreads," National Underwriter, June 2002.

[9] K. H. Northcote, G. G. Beckmann, E. Bettenay, H. M. C hurchward, D. C. Van Dijk, G. M. Dimmock, G. D. Hubble, R. F. Isbell, W. M McArthur, G. G. Murtha, K. D. Nicolls, T. R. Paton, C. H. Thompson,
A. A. Webb, and M. J. Wright, Atlas of Australian Soils, Sheets 1 to 10 , CSIRO Aust. and Melbourne University Press: Melbourne, 1960-1968.

[10] L. Hughes, "Climate change and Australia: Trends, projections and impacts", Austral Ecology, pp. 423-443, 2003.

[11] A. Mills, P. E. D. Love, and P. Williams, "Defect costs in residential construction", Journal of Construction Engineering and Management, vol. 135, no. 1, pp. 12-16, 2009.

[12] J. E. Holland, The Design, Performance and Repair of Housing Foundations, Melbourne: Swinburne Institute of Technology, 1981.

[13] C. W. Thornthwaite, "An approach toward a rational classification of climate," Geographical Review, vol. 38, pp. 55-94, 1948.

[14] P. Devasenapathy, T. Ramesh, and B. Gangwar, Efficiency indices for agriculture management research, New India Publishing Agency, New Delhi, India, 2008.

[15] Aust Roads-NSW. (2004). Impact of climate change on road infrastructure. [Online]. Available: http://www.bitre.gov.au/publications/2004/files/cr_001_climate_chan ge.pdf

[16] H. Arampamoorthy and J. Patrick, Design Moisture Condition Guidelines for Pavement Design and Material Assessment, Report, Opus International Consultants, Central Laboratories, Lower Hutt, New Zealand, October 2010.

[17] M. Philp and M. Taylor, "Beyond agriculture: exploring the application of the Thornthwaite Moisture Index to infrastructure and possibilities for climate change adaptation." ACCARNSI Discussion Paper - Node 2; Urban Planning, Transport and Social Inclusion, NCCARF, Australia, 2012.

[18] A. Grundstein, "Evaluation of climate change over the continental United States using a moisture index," Climate Change, vol. 93, pp. 103-115, 2009.

[19] D. Lopes and N. Y. Osman, "Changes of the Thornthwaite Moisture Indices in Victoria from 1948-2007 and the effect on seasonal foundation movements," Australian Geomechanics Journal, vol. 41, no. 1, pp. 37-48, Australia, 2010.

[20] AS, Australian Standards Limited., AS 2879-1996: Residential slabs and footings (updated with amendments 1, 2, 3, and 4), Sydney, NSW, 1996.

[21] G. McCabe Jr. and D. M. Wolock, "Effects of climatic change and climatic variability on the Thornthwaite moisture index in the Delaware River basin," Climatic Change, vol. 20, issue 2, pp. 143-153, February 1992.

[22] S. Leao et al., "TMI for urban resilience: measuring and mapping long-term climate change on soil moisture," in Proc. $7^{\text {th }}$ Australasian Housing Researcher's Conference, February 6-8, 2013, Fremantle, WA, Australia.

[23] DPCD, Department of Planning and Community Development, Victoria in Future: Population and Household Projections 2011-2031 for Victoria and Its Regions, DPCD, Melbourne, Victoria, Australia, 2012.

[24] CoGG, City of Greater Geelong, “Armstrong Creek Urban Growth Plan Volume 1," City of Greater Geelong, Vic, Australia, 2008.

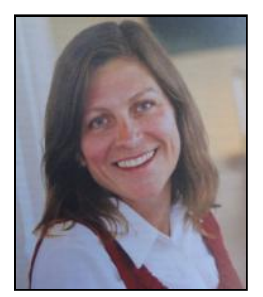

Simone Leao is a lecturer in Urban Technologies in the School of Architecture and Built Environment of Deakin University, in Victoria/Australia. She has a bachelor of science in engineering with emphasis on environmental pollution (B.Sc.) in Brazil in 1994, a master of science in urban and regional planning with emphasis on urban-environmental planning M.Sc.) in Brazil in 1997 and a doctorate in Geomatic Engineering with emphasis on spatial computer modeling and simulation (Ph.D.) from The University of Melbourne, Australia in 2002. Throughout her 18-year career these three distinct fields have been interwoven having the city as the linking element. Dr. Leao's main research interest is in better understanding the interdependencies between built and natural environments. With this goal she works on developing knowledge and methodologies to assist in the generation of new or regeneration of existing areas with awareness and consideration of the challenges faced by urban and environmental planning, such as sustainable development goals, climate change processes, and high urbanization rates. 